\title{
Teaching and learning of information literacy in some selected institutions of higher learning in KwaZulu-Natal and Malawi
}

\author{
George Chipeta 1 \\ Dept of Library and Information Science, Mzuzu University, Malawi \\ georgechipeta@yahoo.com \\ Daisy Jacobs ${ }^{2}$ \\ Dept of Library and Information Science, University of Zululand, South Africa \\ djacobs@pan.uzulu.ac.za \\ Janneke Mostert ${ }^{3}$ \\ Dept of Library and Information Science, University of Zululand, South Africa \\ jmostert@pan.uzulu.ac.za
}

\begin{abstract}
Received 21 October 2008
Accepted 20 May 2008

Information literacy (IL) is a set of abilities that enable individuals to recognise when information is needed and to subsequently locate, evaluate, and utilise the required information. It enables people to interpret and make informed judgments as users of information sources, and also to become producers of information in their own right and thereby more active participants in society. Information literacy is the basis of lifelong learning. It is common across all disciplines, all learning environments, and all levels of education. This study, which was conducted among academic and library staff and students at the University of Zululand (Unizul) and the Durban University of Technology (DUT) in KwaZulu-Natal (SA) and Mzuzu University (Mzuni) in Malawi, reports on the offering and teaching of IL in these institutions of higher learning. The findings reveal that $I L$ is offered and taught as a module at Unizul and as a course at Mzuni by their respective Departments of Library and Information Science, though not across all the faculties. At DUT, IL is only offered and taught by the library during the Library Orientation programme, campus wide. Problems encountered in the teaching and learning of IL include inadequate time, lack of computer skills, inadequate venues and equipment for teaching and students' practicals, and lack of cooperation. The study recommends that the module or course of IL should be incorporated into the university curricula of all three institutions, and the DUT should introduce a dedicated module or course in information literacy and embed it into the students' course materials. The three universities should also advertise to academic staff, students and decision makers the importance of having modules or courses in IL.
\end{abstract}

Keywords: Information literacy, information need, lifelong learning, library orientation, computer skills, tertiary institutions, technology, information sources

\section{Introduction}

The American Library Association (ALA, 2007: I) defines information literacy as "a set of abilities which enable individuals to recognise when information is needed, and possessing the ability to locate, evaluate, and utilise the needed information". Living in the Information Era these abilities have become imperative in virtually all life situations, but specifically in the learning/educational environment.

Tertiary institutions are centres of learning and knowledge generation, meaning that students, academic staff, administrative staff, researchers and librarians work with information. Therefore the ability to search, identify, locate, retrieve and use information independently becomes a necessity for students whose purpose for attending a tertiary institution is to gain as much knowledge and information as possible to enable them to functional optimally in their chosen occupations. According to Barton (n.d: I-2) information literate students access, evaluate and use information from a variety of sources, communicate effectively, and reflect on the process as well as the product. The general lack of access to information sources experienced on the African continent, both for educational and leisure purposes, often results in information illiterate students, ill-prepared for the rigours of information searching and retrieval at tertiary level. For this reason a deliberate programme designed to teach and learn information literacy (IL) to students should be incorporated in all universities' curricula to assist students in gaining the required abilities to interrogate and utilise information.

One of the researchers, based on his experience as a student assistant in the Department of Library and Information Science and the Library at the University of Zululand, as well as being an assistant lecturer at Mzuzu University in Malawi, observed that most undergraduate students do not possess the skills necessary to conduct their research and search for information. They rely heavily on their lecture notes and on library staff in their search for information, despite having been taught and equipped with IL skills during their first year at the university. One is thus led to ask: what and where is the problem, and why are students not performing as expected with regard to the application of IL? 
The purpose of this study was therefore to investigate the teaching and learning of Information Literacy in institutions of higher learning in KwaZulu-Natal and Malawi. Specifically, the study intended to achieve the following objectives:

- To determine the status of IL teaching is on each campus.

- To establish the responsibility for the teaching of Information Literacy or library orientation programmes, and what problems are encountered when presenting classes.

- To determine students' perception of their ability to identify, locate, retrieve and use information sources independently.

- To propose recommendations to all stakeholders concerned with Information Literacy curriculum development regarding the effective teaching and learning thereof.

The study included three institutions, i.e two institutions of higher learning in the KwaZulu-Natal province, namely the University of Zululand (Unizul) situated $15 \mathrm{~km}$ outside Empangeni, and the Durban University of Technology (DUT) in Durban; and one institution in Malawi, the Mzuzu University (Mzuni) in Mzuzu. Unizul and DUT were selected because they represent various groupings in the country. The Unizul is a comprehensive rural-based university while the DUT is an urban institution. Mzuni represents both urban and rural settings. The study excluded the other institutions in South Africa and Malawi because distance, cost and time prevented their selection.

\section{Literature review}

Technological advancement has resulted in the proliferation of information to the point that most individuals find themselves faced with diverse, abundant information choices in all spheres of life, be it in their academic studies, places of work or in their personal lives. This information is readily available in libraries, community resources, special interest organisations, the media, and on the Internet. Increasingly, information comes to individuals in unfiltered formats, raising questions about its authenticity, validity, and reliability (ALA, 2007:2).

According to CILIP (2006:n.p), IL is the part of knowledge or learning that revolves around the acquisition of a series of skills or competencies. An information literate individual cares about the quality of the answer to what he/she is investigating, and is prepared to work to guarantee that quality. Information Literacy is relevant to, and is viewed as an important skill to be learned and used in, primary and secondary schools, in further and higher education, and in business and leisure (CILIP, 2006: n.p).

\section{I Benchmarking information literacy in institutions of higher learning}

According to De Jager and Nassimbeni (2002:3), benchmarking is a strategic assessment tool commonly practised in the business sector environment. It essentially consists of comparing best practices with one's own practice in order to ensure continuous improvement and attain excellence. An important product of such an initiative is "the discovery of innovative approaches ... as enhancement of current practices is rarely sufficient to ensure future excellence" (Meade in De Jager and Nassimbeni, 2002:3).

According to the Council of Australian University Librarians (CAUL, 200 I:4), Information Literacy standards provide a framework for those wishing to embed IL in the design and teaching of educational programmes. In addition, the standards outline the process by which academics and librarians assess specific indicators, showing whether or not an individual is information literate. These standards are equally useful to the students because they provide a framework for their interaction with information in any given environment. The standards also help develop their awareness of the need for a meta-cognitive approach to learning, making them conscious of the explicit actions required in order to recognise need, and gather, analyse and use information. The Seven Pillars of Information Literacy (SCONUL 1999) describe outcomes and provide examples of students' progress on their path to becoming information literate. The outcomes serve as guidelines for academics and librarians in developing local methods for measuring students' learning.

Azmi (n.d:149) notes that because Information Literacy augments students' competency in the evaluation, management and use of information, it is now considered by several regional and discipline-based accreditation associations to be a very important competency in university students. These benchmarks or standards are explained as part of the Information Literacy models, of which several are in use today.

\subsection{Information literacy models}

As mentioned in the previous section, various models such as the Big6 Skills model by Eisenberg and Bob Berkowitz (1990), the Information Search process by Kuhlthau (1993), the Research Process Model by Stripling and Pitts (1988), and the Pathways to Knowledge by Pappas and Tepe (2002) exist. Top among them, however is the 'Seven Pillars of Information Literacy model', developed by the SCONUL advisory committee on Information Literacy (1999:6), which is illustrated on the next page in Figure I.

SA JnI Libs \& Info Sci 2009, 75(I) 


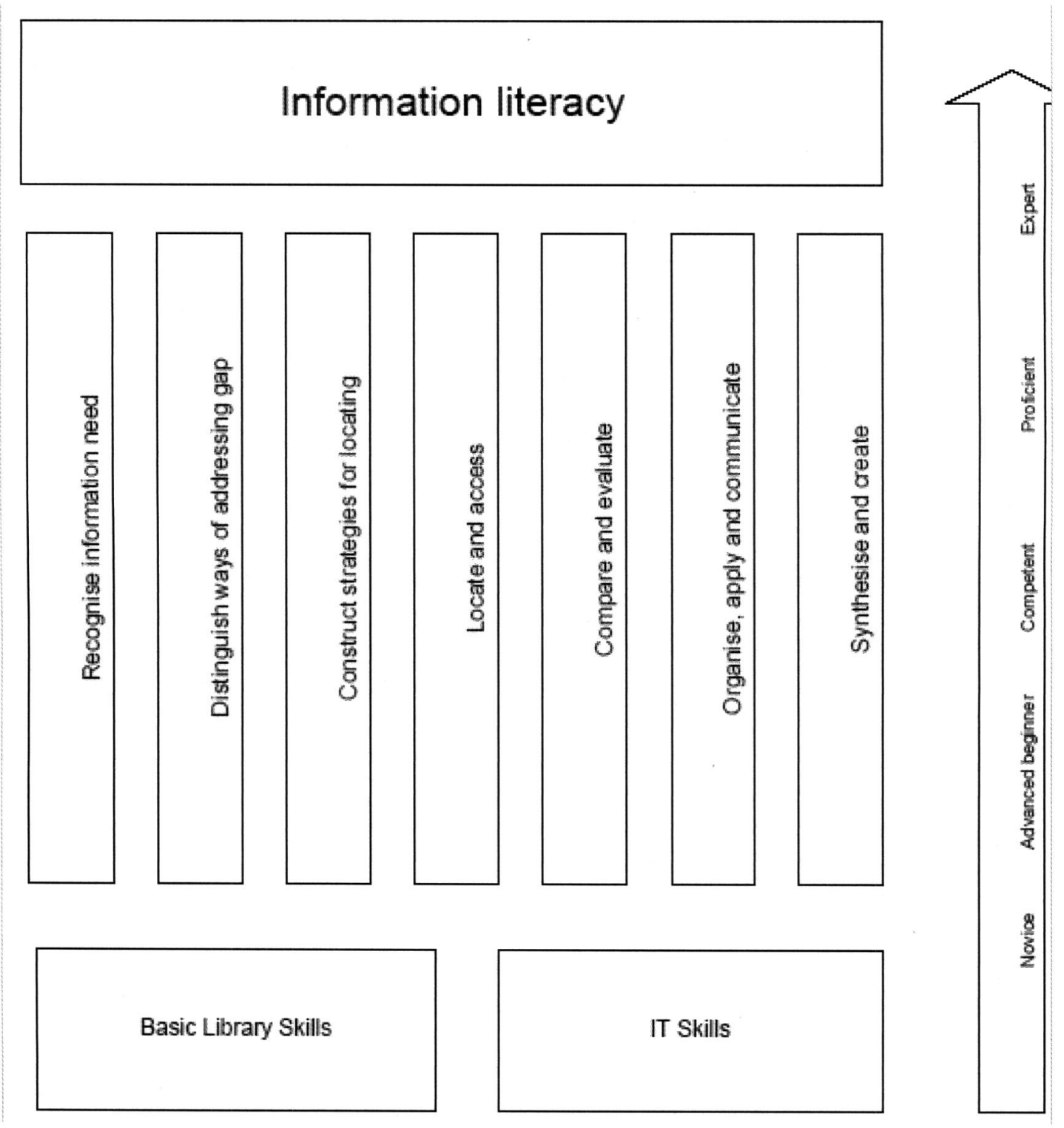

Figure: 1 Information skills model. Source: SCONUL (1999)

In the following section an attempt is made to compare this model with the others mentioned. The seven pillars of information literacy model has seven competence levels, explained below.

\subsection{The ability to recognise a need for information}

This is considered to be the first stage in the information seeking process. An information user is characterised as 'blank' in terms of their awareness of what their information needs are. According to Mostert (2004:124), the term 'need' can be defined as an individual's sense of the lack of something. Belkin (in Kituyi-Kwake, 2007:82) notes that an information need is present when a gap, uncertainty or deficiency in a person's cognitive state is recognised. Belkin adds that this deficiency prevents a person from making sense of the surrounding world, and to this end it is described as an "Anomalous State of knowledge" (ASK). This compares to task definition in the Big6 Skills model, wherein a user determines exactly what the problem is and the specific information needs related to the problem. It also relates to task initiation in Kuhlthau's information seeking process model. This is the stage at which an individual first becomes aware of the lack of knowledge necessary to accomplish an assignment, and often feelings of uncertainty and apprehension ensue. At this stage, the task is to recognise a need for information. In order to address the problem, a person is driven to seek information by, for instance, discussing ideas with others, including peers and experts, and browsing through different sources to identify a research topic or other information need. This in turn leads the information seeker to explore general information resources to increase familiarity with the topic. Often this also involves brainstorming, thinking about possible topics and tolerating uncertainty. The information seeker then selects the topic for research. 
A person chooses a broad topic and gets an overview of the topic, also known as recalling, which entails fact-finding, such as "reporting on the information" in Strippling and Pitts' research process model (1988: n.p) [also known as REACTS]. In other words, it involves searching for answers by posing questions, such as whether or not the topic chosen will meet the user's research interests; and finding answers to such questions. It also entails exploring various forms of literature by reading, watching and listening. In their model, Pappas and Tepe (2002: I-2) consider this to be the stage of appreciation and enjoyment. Appreciation and enjoyment entail an awareness of one's information requirements. The authors argue that appreciation fosters curiosity and imagination, which in turn lead to discovery in an information seeking activity. As information users go through the stages of information seeking by viewing, listening, and reading, their appreciation grows and matures.

\subsubsection{The ability to distinguish ways in which the information gap may be addressed}

The second step of the information process in the seven pillars of information literacy model entails an information user being knowledgeable about both print and non-print information resources, selecting the information resources that would accomplish a user's research task, and being able to understand issues affecting access to such resources (SCONUL, 1999:7). Baker (2005:1-2) compares this stage to "formulating questions that would guide research and planning for research production" in Pitts and Strippling's (1998:np) Research Process model, and the pre-search stage in Pappas and Tepe's (2002:I-2) pathways to knowledge model. Baker (2005:5) is of the opinion that the research process model stage involves analysing, through examination, whether the questions lay a good foundation for the research task and whether the research plan is feasible. The researcher then organises the information to fit the research task at hand.

During the pre-search stage, Pappas and Tepe (2002:2) claim that information seekers are able to make a connection between their topic and the knowledge that they already have in order to explore the relationships between subtopics. This supports the information seekers' questioning what they know about their topic and what they would wish to know.

\subsubsection{The ability to construct strategies for locating information}

The third step in the Seven Pillars of Information Literacy model consists of articulating information needs to match information sources, developing a systematic method appropriate to the information needs, and understanding the principles of construction and generation of databases. Baker (2005:1-2) compares this stage to the information seeking strategies of the Big6 Skills model and 'search' in the Pathways to Knowledge model. During information seeking, and in order for an individual to find topic ideas or the amount of information needed, he/she would need to consult various forms of literature, such as journal articles and books, on his/her subject. This also means acquiring a wide range of information sources and selecting the best from all the possibilities. This entails the seeker's assessment of the value of various types of print and electronic resources, such as CD-ROMs, databases, browsing the Online Public Access Catalogue (OPAC) and so on.

\subsubsection{The ability to locate and access information}

The fourth stage of the seven pillars of information literacy model states that an information user should be able to develop an appropriate search technique, such as the use of Boolean operators, communication and information technologies, appropriate indexing and abstracting services, and citation indexes and databases; and use current awareness methods to keep up to date. The stages that are germane here include the Big6 Skills' "location and access"; "find, analyse and evaluate resources" in Pitts and Strippling's research process model; and "search" in the pathways to knowledge model. Eisenberg and Berkowitz (1990:n.p) note that this stage is concerned with the individual selecting the most appropriate investigative methods by developing a research plan, and by identifying keywords, synonyms and terms related to the information needed. The user thereafter constructs a search strategy using appropriate commands for the information access tool(s) selected, such as the use of the Boolean operators "AND", "OR" and "NOT", truncation, proximity operators for databases/search engines and the use of OPAC, indexes and abstracts. He/she goes on to retrieve information in a variety of formats using various information access tools, classification schemes and other systems, such as call number systems or indexes, to locate information resources within a library. In the search stage of the pathways to knowledge model, Pappas and Tepe (2002:3) state that information seekers identify appropriate information providers such as libraries, records and archives centers, museums and so on; select information resources and tools such as indexes, people, the Internet, the media and references resources; and then plan and implement a search strategy to find information relevant to their research question or information needs. This they can do by scanning, conducting interviews and confirming information sources, recording information in order to determine its relevance, and exploring and browsing widely.

SA Jnl Libs \& Info Sci 2009, 75(I) 


\subsubsection{The ability to compare and evaluate information obtained from different sources}

The fifth stage of the Seven Pillars of Information Literacy model signifies that users of information should be aware of bias and authority issues, the peer review process of scholarly publishing, and the appropriate extraction of relevant information. This can be compared to "evaluation" in the Big6 skills model, "search closure" in Kuhlthau's information search process, "evaluating evidence or taking notes and compiling a bibliography" in the research process model, and "interpretation" in pathways to knowledge. Eisenberg and Berkowitz (1990:n.p) observe that the information seeker assesses the quantity, quality, and relevance of the search results in order to determine whether alternative information access tools or investigative methods should be utilised; identify the gaps in the information retrieved; and determine if the search strategy should be revised. The information seeker repeats the search using the revised strategy if or when necessary, summarises the main ideas extracted from the information gathered, and examines and compares information from various sources in order to evaluate their reliability, validity, accuracy, authority, timeliness, point of view and/or bias. $\mathrm{He} /$ she should also be able to recognise the cultural, physical or other contexts in which the information was created, and understand the impact of context when interpreting the information. At this stage, the information seeker may feel a sense of relief, satisfaction or disappointment. The researcher and student rechecks sources for information that might have gone unnoticed from the outset and confirms information and bibliographic citations relevant to the focus and research questions. Strategies used include returning to the library to sum up the search and keeping books until completion to recheck information.

As for "evaluating evidence or taking notes and compiling a bibliography" in the Research Process model, Baker (2005:5) writes that this involves judging information on the basis of authority, significance, bias and other factors.

\subsubsection{The ability to organise, apply and communicate information to others in ways appropriate to the situation}

This stage calls for people in academia to cite bibliographic references in their academic work, construct a personal bibliographic system, apply information to the problem at hand, communicate information effectively using the appropriate medium, and understand issues pertaining to copyright and plagiarism (SCONUL, 1999:6). This can be translated to "information use" in the Big6 Skills model and "communication" in the pathways to knowledge model. According to Pappas and Tepe (2002:3), the communication stage allows users to organise and present new knowledge as it relates to their research questions or information needs. In applying information, individuals choose an appropriate communication format and respect intellectual property. In sharing knowledge, the information user composes, designs, edits, revises and uses the most effective medium (eg videos, reports and animation) to convey the information. The information user should also understand the cultural, ethical, legal, and socio-economic issues surrounding information, and identify and articulate issues that relate to privacy. In addition, he/she needs to note security in both the print and electronic environments, identify and articulate issues in relation to free versus fee-based access to information, identify and discuss issues in relation to censorship and freedom of speech, and demonstrate an understanding of intellectual property, copyright and fair use of copyright materials. In order to avoid issues of plagiarism, the information user should acknowledge information sources, selecting an appropriate citation style in project reports, dissertations and theses.

\subsubsection{The ability to synthesise and build upon existing information, contributing to the creation of new knowledge}

"Synthesis" in the Big6 Skills model by Eisenberg and Berkowitz, "presentation" in Information Search Process by Kuhlthau, and "establish conclusions/organise information in outline and create and present final product" in the research process model by Pitts and Striplling fit in the seventh stage of the Seven Pillars model. In synthesising information, according to Eisenberg and Berkowitz (1990:n.p), the information user brings information together and links what he/she has learnt to what he/she already knows. The individual chooses a communication medium and format that best supports the purposes of the product and the intended audience. In the case of a researcher or student, this is accomplished by writing a draft that links various bits and pieces of information into one coherent whole, and revising the draft a number of times in order to improve its coherence before submission. Kuhlthau (1993:n.p), however, views this stage as presentation. This is when the task is to complete the search and accomplish the assignment. A sense of relief is common, with satisfaction if the search has gone well or disappointment if it has not. Finally, the information user has to combine concepts in order to make potentially useful primary statements with supporting evidence; and integrate the prior and new information, including words and ideas, in a manner that supports the purposes of the project. By establishing conclusions and organising information in an outline, an information user, according to Pitts and Strippling (1988: n.p), draws conclusions by creating a personal perspective based on the information obtained. The outline should logically organise conclusions and evidence. In creating and presenting the final product, Pitts and Strippling (1988: n.p) are of the view that this should reflect whether or not the content is satisfactory. 


\subsection{The teaching of information literacy in South African Institutions of higher learning}

There are several information literacy initiatives in South Africa. One such initiative, the most prominent in fact, was the establishment of the Information Literacy (INFOLIT) project in 1995. According to Underwood (2002:5) the primary objectives of INFOLIT were, among others, to promote the concept, value and importance of information literacy and to launch a series of pilot projects, explore and establish means of spreading information literacy education in the Western Cape region. The tangible outcomes of the INFOLIT project has been the recognition of the importance of IL at the University of Stellenbosch, University of Cape Town, Peninsula Technikon, Cape Technikon and the University of the Western Cape. The INFOLIT project also culminated in sponsoring the development of a Web-based Information Literacy course. The site is meant to help users find, evaluate, use and communicate information. It is available at all the tertiary institutions in the Western Cape Province (Underwood, 2002:7). Underwood (2002:8), reports that the INFOLIT project also led to the establishment of a Centre for Information Literacy at the University of Cape Town. The members of staff of the Centre are responsible for working with the academic staff of all the university's faculties in order to develop strategies for the integration of Information Literacy within the faculties' curricula. A series of discipline-based workshops on Web searching were developed using a template. The workshops were delivered on request to academic and library staff and students at each of the five institutions in the Cape region (Underwood, 2002:8).

According to De Jager, Nassimbeni and Underwood (2007:143), most institutions of higher learning offer library orientation or training that includes the use of the OPAC, electronic databases, citations and referencing. The authors also note that there is growing evidence of a greater number of IL modules being embedded in various curricula. While most of the courses are still generic stand-alone courses, others are credit bearing. Most institutions have a librarian whose primary responsibility is IL education, very often supported by subject librarians who offer training in their specific fields or disciplines. Some of the training is delivered in classrooms or computer laboratories, while other forms of training are offered virtually, through platforms such as Web-CT. A training librarian makes the point, however, that at her institution they are unable to offer an online course because many of their students come "from rural areas, farms and townships where there are no libraries and computers" (De Jager, Nassimbeni and Underwood (2007: 143).

At the former Rand Afrikaans University the university launched a multimodal approach to teaching and learning in 2003. The multimodal approach was aimed at optimisation, learning and assessment, and has been defined as the use of different media or modes of delivery of teaching. The different media and technologies used in this integrated, multimodal learning environment include: lectures, support from tutors, paper-based learning guides, interactive CDs, textbooks, videos, videoconferencing and the Web (electronic classes based on WebCT software and offered to students via the Edulink virtual learning environment portal) (Molepo and van Vuuren 2005: I44).

According to Kibirige (2005:131), the learning and teaching processes at Monash University, South Africa., involve, in some instances, customised classes for groups of students for search assistance related to a specific assignment. Such a session covers the Voyager catalogues as well as reference works, search strategies and online databases relevant to an essay topic. Through liaison between the library and the Center for Learning and Teaching, some lecturers attend information literacy workshops taught to subject groups on an ad hoc basis. Other iniatives include curriculum integrated sessions, where there is one formally scheduled session on the academic timetable - a two-hour class on "Doing research on the Internet" - as part of a first year course in Contemporary Studies. Students complete an assignment for credit towards their semester mark, and develop the skills that are necessary for effective Internet research by completing specific exercises. This model could be extended to other course units (Kibirige, 2005: 131).

\section{Methodology}

Qualitative and quantitative approaches were both used in this study, in the form of a survey consisting of questionnaires and observations for data collection from the students, and interviews in the case of academic and library staff. A quota sampling technique was used on 408 students, of whom 287 responded. A sampling ratio of $1.3 \%$ was used across all three institutions to come up with the sample. The population in this study was first categorised according to faculty, level of study (whether undergraduate or post-graduate) and gender before being selected haphazardly. Permission had to be sought and granted from the institutions under investigation. For the survey, self-administered questionnaires, containing both open and closed ended questions, to cater for both qualitative and quantitative responses, were handed out. Observations on the students' ability to search, locate and retrieve information were also done during the same period as the questionnaires were distributed.

The study used purposive sampling, which is also a judgemental form of sampling. The researcher, based on his knowledge of the population, handpicked the individuals according to their relevance to this study. The study targeted and interviewed three lecturers in the respective Departments of Library and Information Science (LIS) responsible for teaching Information Literacy, and three library staff from the selected institutions. Lecturers in the Departments of LIS 
were targeted because most IL offerings and teachings are housed in these departments. Library staff were selected because libraries conduct orientation programmes in which some components of IL are taught. Hence, their inclusion was viewed as important. Data was analysed using the Statistical Package for Social Sciences (SPSS). The results were represented qualitatively and quantitatively using tables, graphs and percentages.

\section{Results}

This section presents the results and discussions of the major findings collated from three sets of data, namely questionnaires, observations of students' information-related behaviour, and interviews with academic and library staff from the three institutions. Issues that are considered to be of major importance are outlined below.

\section{I Status of teaching of information literacy}

The offering of the course of IL in the universities under study was considered to be of great significance in this paper, because it lays the foundation for the teaching and inculcation of IL skills in the students. From the research it emerged that Information Literacy is offered and taught as a module or course by the Departments of Library and Information Science at the University of Zululand and Mzuzu University, where it is embedded in the departments' curricula. While it is not formally offered by the Durban University of Technology, it forms part of the library orientation programme. At both Unizul and Mzuzu it also forms part of the library orientation programme, which it is not compulsory to attend.

The methods of designing the formal courses differ amongst the two institutions who offer it. Whereas the best practice for the design and review of the curriculum is through the involvement of various stakeholders, such as librarians, administrators, lecturers, and curriculum designers, this is not always the case. In the case of Mzuzu University, the LIS Department hosts a workshop, where participants, mainly lecturers from the LIS Department and librarians from across the country, deliberate on and design a curriculum that is acceptable to all parties. This is reviewed on an annual basis. At the University of Zululand, however, the course is designed and reviewed periodically by the lecturer concerned, in consultation with the Head of the LIS Department. No external input is sought.

From the interviews with staff members it was clear that the teaching of the formal courses is the responsibility of the lecturers in the respective departments of Library and Information Science, while the informal library orientation programmes were the responsibility of a senior library staff member.

In terms of how the formal courses are offered the responses indicated that it was mostly by way of lectures in class, group discussions, and hands-on use of the library (browsing and using the Open Access Public Catalogue and other library resources). Though strong emphasis is placed on theoretical modes of teaching only, it would seem that a practical component is available, specifically at Unizul, as 9 (50\%) of the 18 students who attended formal classes indicated that they received instruction by way of both practicals and theory. The informal library orientation programmes took the form of a theoretical introduction to the library, a walkabout in the library to familiarise students with the whereabouts of the information sources, and a one hour practical hands-on introduction to the OPAC. Attendance of the orientation programmes is not compulsory and skills learned are not tested or credited to the student.

A concern is the fact that very few $(3 \mathrm{I} ; \mathrm{II} \%)$ of the student respondents indicated that they are aware of the formal course in Information Literacy. Quite possibly, this is because the module or course is only embedded in the curricula of the Departments of Library and Information Science and Communication and Agriculture Science at the University of Zululand, and the Department of Library and Information Science at Mzuzu University. As students are mostly concerned with what is prescribed to them in the curriculum,they will mostly remain unaware of the IL course's existence.

From the above it should then stands to reason that attendance numbers of the IL courses would be low, which was in fact the case as only $18(28 \%)$ of the respondents from the three institutions indicated that they attend the formal courses in information literacy.

\subsection{Student perception of their ability to identify and locate sources in the library independently by using the OPAC, indexing and abstracting journals}

From the results presented in Table I below, it is interesting to note that all the students who indicated that they had received formal training felt confident that they could identify and locate information sources with ease using a variety of information retrieval tools. This finding was confirmed by the researcher's observations of the searching skills of the students, where it was found that students who had some formal training very easily traced the required documents and located them very easily on the shelves. However, those with no formal training spent many hours searching and were often frustrated at not finding what they wanted. This was a common trend at both Unizul and Mzuni. The observed students at DUT, however, had no problems locating and retrieving documents. The possible reason for this is discussed in the following paragraph. 


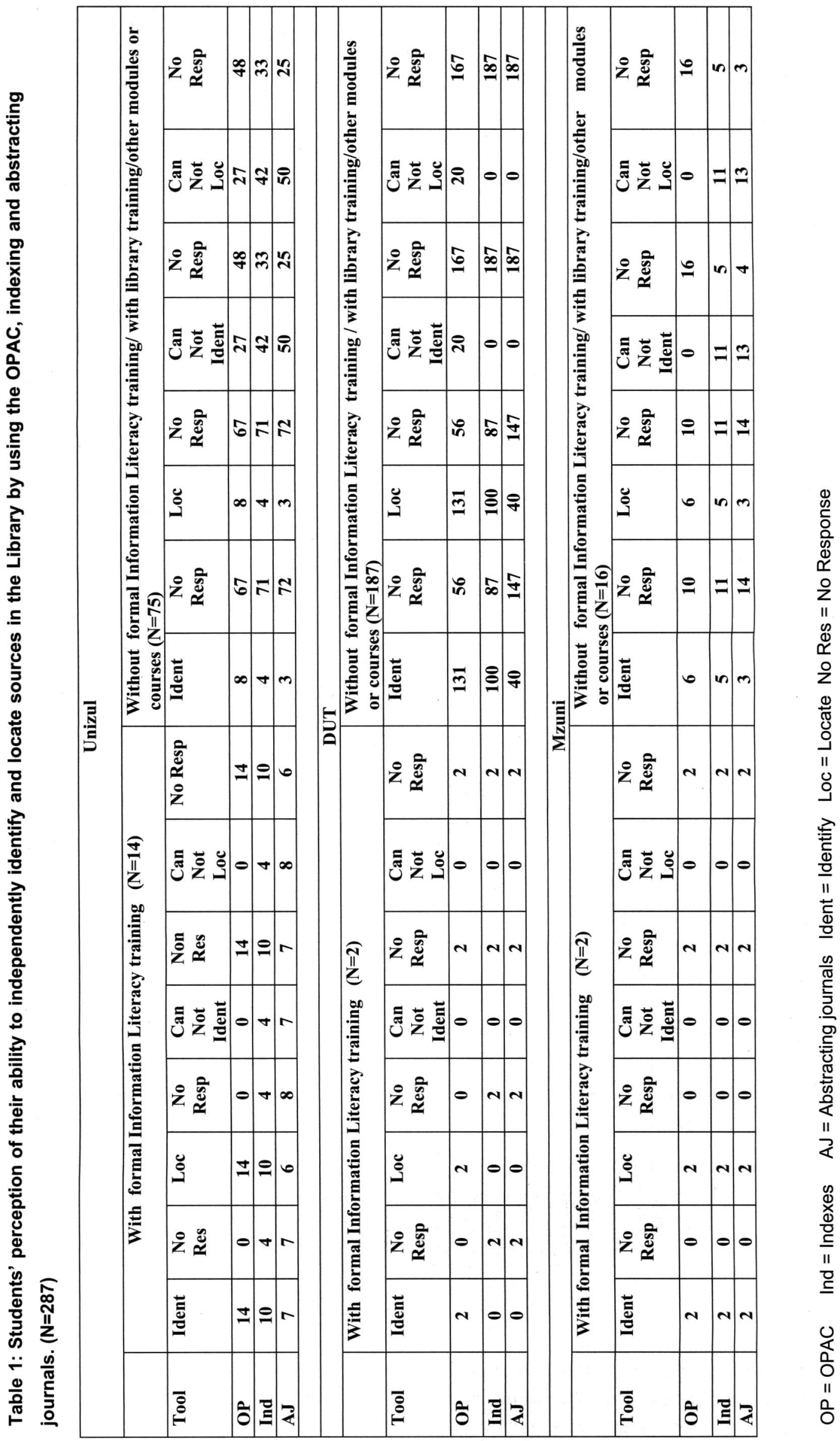




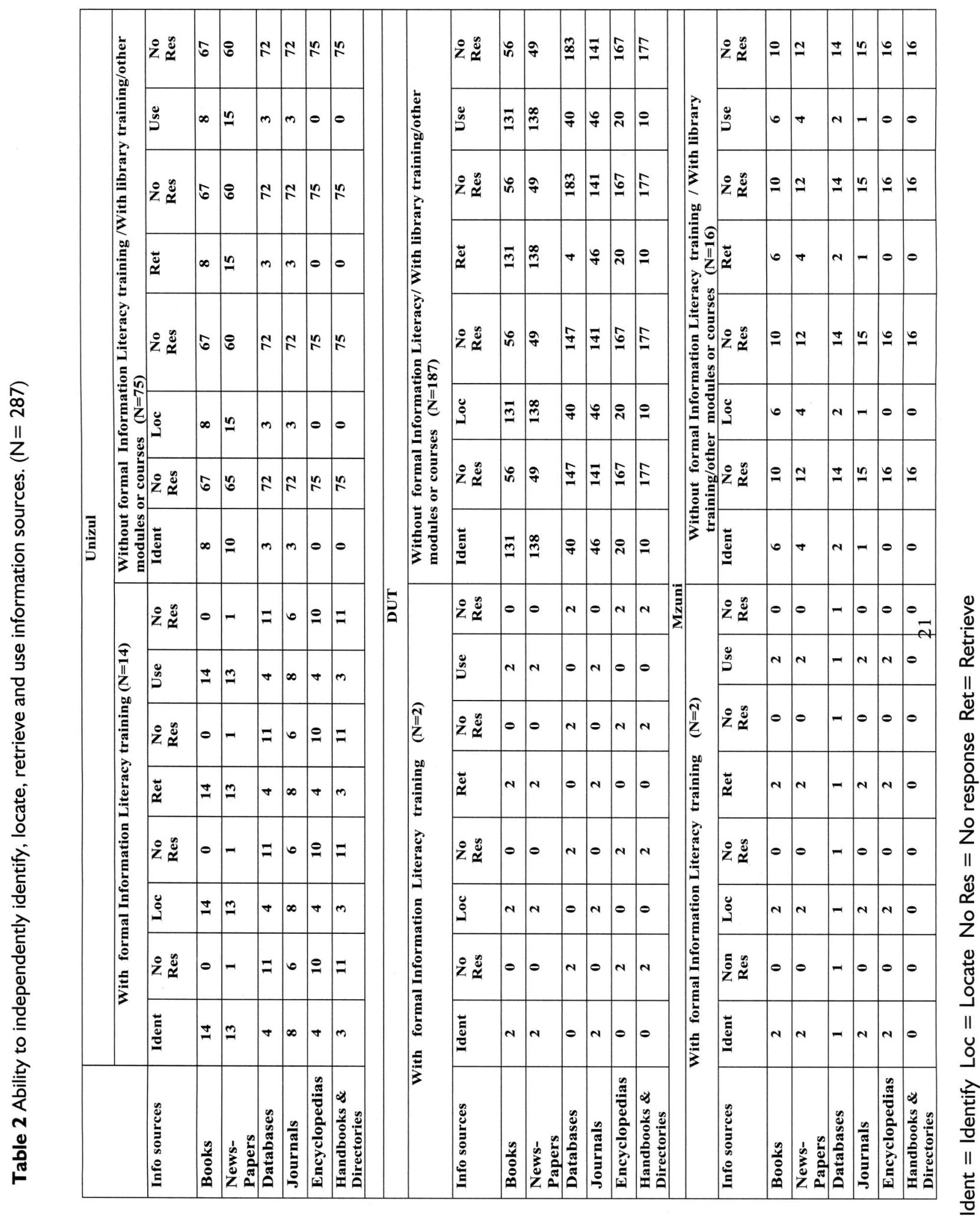

An interesting trend was that the students without formal training, but who probably attended the library orientation programme at both Unizul and Mzuni, did not feel too confident in their ability to either identify or locate information sources (a no-response to this question was seen as an indication of an inability to use the specified tool) while those at DUT, where only library orientation is offered, displayed a lot of confidence in their information seeking abilities (see 
Table I). This then raises the question of the quality of the library orientation programmes at the institutions. During the interviews with the librarians at Unizul and Mzuni, they indicated that they taught topics such as library rules and policies (Unizul), information retrieval skills (Unizul and Mzuni), how to use the OPAC and other retrieval tools (Unizul and Mzuni), online databases (Unizul), classification and arrangement of information sources in the Library (Mzuni) and the citing and referencing of academic works (Mzuni). At DUT, however, the orientation programme consisted of eight units and included topics such as the nature and need for information, the Dewey decimal Classification, I-Link-OPAC, printed sources of information, e-resources, how to locate information using different retrieval tools, evaluation of information resources, plagiarism and referencing. From the above description it would seem as if the DUT library programme offered enough in-depth knowledge to equip the students with the necessary information retrieval skills.

\subsection{Student's perception of their ability to identify, locate, retrieve and use information sources}

The respondents were asked to indicate how they perceived their abilities to find locate retrieve and use various information sources commonly used by students for educational purposes. As was the case with the previous section (4.2), the same trend was detected among the students from the respective institutions, where the students from DUT were much more familiar with seeking, finding and using a variety of sources (see Table 2).

\subsection{Challenges faced in the teaching and learning of information literacy or the library orientation programme}

During the interviews with both the Library and Information Science Departmental staff at Unizul and Mzuni, as well as DUT, the librarians responsible for the library orientation programmes at all three the institutions the following challenges were identified.

\subsection{Time}

Time plays a very important role in the teaching of IL. The shorter the period of teaching, the more likely it is that the teaching is ineffective, and therefore important information skills cannot be adequately imparted to the students. If, on the other hand, the teaching period is longer, there is a higher likelihood that students would grasp the topics under discussion.

Among all the staff members interviewed this was seen to be a common problem. Especially for the library orientation programmes, only one-hour slots per student group were allocated, and this was seen as totally inadequate to disseminate and equip the students with the practical skills necessary for effective information seeking. Even for the Departmental staff who had a whole term to teach Information Literacy, this was mentioned as being inadequate time, especially in terms of practical work. Even among the student respondents this was identified as problematic.

\subsubsection{Computer literacy}

Some topics, such as the use of the OPAC, databases, search engines, and search and retrieval in the module or course of IL, involve the use of the computers and the Internet. Therefore students need to be computer literate. The lack of computer literacy was a problem mentioned by all the staff members interviewed. The inability to operate computers sufficiently slowed down the teaching during practical sessions, and this was particularly frustrating to the Library staff since they only had one hour to teach students all that they need to know about the library and information seeking. This then often resulted in sessions being virtually fruitless as tasks could not be completed or practised.

\subsubsection{Lack of computers}

The teaching of $\mathrm{IL}$ also requires a setting where there are computers for students' practicals. This contributes to a smooth teaching and learning environment. The shortage of equipment and venues means limited access to computers and a subsequent shortage of adequate practicals. This was found to be a perennial problem at all the universities, especially in the libraries, which needed the equipment on-site for practical orientation. The staff teaching the course experienced the same problem, having to make use of computer laboratories, which were most of the time doublebooked to other courses (Unizul) or always used by Computer Science students, not leaving much room for any other classes (Mzuni). This often leads to a situation where students just did not pitch up for classes, as they knew about these problems.

\subsubsection{Lack of collaboration between academic and library staff}

Where the academic staff did not see the need for any form of collaboration, especially in terms of curriculum development, all the library staff interviewed lamented the lack of collaboration, especially in terms of sending, or making students available, to attend library orientation programmes. One of the library staff members also complained that 
students are sometimes sent to the library for an orientation class without prior arrangement with the librarians, leading to a situation where the librarian is ill-prepared or not in a position to handle them at that point in time

\section{Discussions}

Though Information Literacy does form part of the formal offerings at both Unizul and Mzuni, it is not a course that is widely taken by the student body at large. Possible reasons for this situation could be a lack of marketing to other Departments by the respective Departments of Library and Information Science (LIS), since the majority of the students who do take the course come from the LIS Departments itself. Other reasons could be that the University academic staff in general does not realise the value of such a course, probably because of ignorance as to what it entails, or because they themselves do not see it as an important aspect of the academic empowerment of students. Another explanation could be that lecturers in each module provide information on aspects of Information literacy such as citation writing, and see it as enough background for writing. The librarians at all three libraries also indicated that some of the lecturers do send students to the library to attend a library orientation programme specifically for that class. This is seen as sufficient knowledge to search and find information. Taking into account the still existing disparities in the access to information sources in the majority of the communities where students originate, it can be safely assumed that students have not been widely exposed to the use of information sources to find and use information. Based on this fact, and as indicated in the literature review, the ideal situation is to have Information Literacy embedded in the curricula across the tertiary institution's academic programmes. As long as Information Literacy is not a compulsory module, the majority of students will find it difficult to engage in the information seeking, use and dissemination process effectively.

In the absence of formal Information Literacy teachings, the library orientation programme needs to fill the gap. From the interviews with the librarians it was clear that the time allocated to each student group is insufficient, especially with the amount of information and skills that need to be disseminated. Combined with this is the student's lack of previous exposure to formal information sources, as well as the lack of computer literacy skills. All these factors necessitate a renegotiation of time allocation between the library and the academic institution. The issue of the allocation of credits for attendance should also be given attention, since it was shown that this is one of the major motivating factors for attendance of library orientation programmes. The fact that the DUT students perceived their information location, use and retrieval abilities as relatively good, compared to the other two universities, is a probable indication that the library orientation programme followed at the institution's library could be a model to be implemented at other tertiary institutions. However, further research should be done, as the positive results could also stem from the fact that this institution is located in an urban area where previous exposure to information sources is more likely.

With the current trend among students to use technology extensively to try and locate information, it becomes even more imperative that Information Literacy be made part of each academic programme, since each source, such as a database, be it in bibliographic or full text format, electronic newspapers, online journals or CD-ROMs, presents its own challenges in terms of locating the source, navigating around it, and eventually extracting the necessary information.

\section{Recommendations}

For Information Literacy to be successfully taught, the necessary resources such as venues to teach and access to sufficient computers are essential. Theoretical teaching alone is not enough, as it does not equip students with the necessary skills to use libraries or individual information sources with confidence. Additionally, enough staff members need to be allocated, also for the library orientation programmes, especially as the latter is sometimes the only exposure students get to a form of Information Literacy teaching. Groups should be small enough to be interacted with so that problems, whether computer illiteracy or inexperience in information seeking, can be solved as they arise. In bigger groups, those with problems are not easily identified and often leave such a lecture as ignorant as before. This was clearly illustrated by the responses in Tables I \& 2 where a large majority of students who potentially should have attended library orientation programmes still could not utilise the library facilities and information sources.

Wider consultation and collaboration with various stakeholders, such as the librarians and staff from other universities who offer similar courses, should be encouraged, especially in terms of curriculum development and issues of concern such as shortage of time and staff to offer Information Literacy or Library orientation programmes. This could result in learning from others and establishing best practices. Though Mzuni has already embarked on such a process it is recommended that the other universities studied should follow suit. Especially the DUT should seriously consider introducing a formal Information Literacy course to build on the work that is already being done by the librarians.

In the interests of the academic empowerment of students, it recommended that both LIS academic staff and librarians market their Information Literacy/library orientation classes aggressively to the academic staff in general and 
lobby for it to be made a compulsory and credit bearing course. In this way, all students are prepared for the rigours of academic discourse and research work, which ultimately is the aim of any academic institution.

\section{References}

American Library Association 2007. Information literacy competency standards for higher education. (Online): http://www.ala.org/ ala/acrlbucket/homepagecontent/contactacrl.htm (Accessed 20 March 2007).

Azmi, H. (n.d). Teaching information literacy skills: a case study of the QU core programme in Qatar University. (Online): http:/ /www.ics.heacademy.ac.uk/italics/vol5iss4/azmi.pdf (Accessed 15 April 2008).

Baker, K. 2005. Baker model. [Online]: http:www//virtualinquiry.com/inquiry/bakermodel.pdf (Accessed 20 February 2008)

Barton, H. n.d. Information literacy: learning how to learn. [Online]: http://www.ri.net/RITTI_Fellows/Barton/infolit.html. (Accessed 5 March 2007).

Chartered Institute of Library and Information Professionals (CILIP) (2006). A short introduction to information literacy.

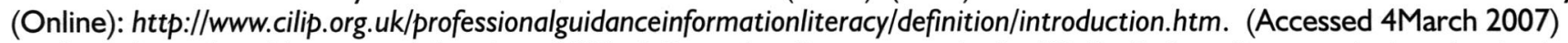

Council of Australian University Librarians 200I. Information literacy standards. [Online]: http://www.caul.edu.au/caul- doc/ InfoLitStandards200I.doc (Accessed I5 March 2007).

De Jager, K. and Nassimbeni, M. 2002. Can they do and do they? Exploring the Information Literacy tuition in South African tertiary institutions. A Paper presented at LIASA (2002): Port Elizabeth, South Africa. [Online]: $h$ ttp://home.imaginet.co.zal liasa/Karin\%20\&\%20Mary2002.rtf (Accessed 10 March 2007).

De Jager, K Nassimbeni, M and Underwood, P. 2007. Libraries, literacies and learning: retrospect and prospects. [Online]: http:/ 174. $125.77 .132 /$ search?q= cache:7qcdUdKMTaQJ:www.dissanet.com/ifla/pdf/ LIASA\%252010\%2520De\%2520Jager,\%2520Nassimbeni\%2520\%26\%2520Underwood.pdf+De +jager, + nassimbeni+and+ Underwood\&hl $=$ en\&ct $=c l n k \& c d=3 \& g l=z a \& c l i e n t=$ firefox- $a($ Accessed 25 March 2007).

Eisenberg, M. and Berkowitz, B. 1990. A Big6 skills overview. [Online]: http://www.big6.com/showarticle.php?id=16. (Accessed 15 April 2007).

Kibirige, S.N. 2005. The current status of Information Literacy training at Monash South Africa. In: Kiondo, E and Msuya, J (eds), User information literacy: case studies from university library programmes in the SCANUL-ECS region. Bristol: INASP.

Kituyi-Kwake, A.W. 2007. The role of information and communication technologies in harnessing information for women in rural development: case studies of South Africa and Kenya. Ph.D Thesis. Kwa Dlangezwa: University of Zululand.

Kuhlthau, C.C. 1993. Information search process. [Online]: http://www.Scils.rutgers.edu/ Kuhlthau/ Information_Search_Process.htm (Accessed I0 June 2007).

Molepo, C. and Van Vuuren, A. V. 2005. User education at the Rand Afrikaans University. In: Kiondo, E and Msuya, J (eds), User information literacy: case studies from university library programmes in the SCANUL-ECS region. Bristol: INASP.

Mostert, B.J. 2004. Parliamentary information sources, systems and services in South Africa and the role of parliamentary libraries and information provision. Ph.D Thesis. KwaDlangezwa: University of Zululand.

Pappas, M.L. and Tepe, A.E. (2002). Pathways to knowledge and inquiry learning. [Online]: http://virtualinquiry.com/inquiry/ pathways.htm. (Accessed 20 March 2007).

Society of College, National and University Libraries. 1999. Information Skills in Higher Education: A Sconul Position paper. [Online]: $h$ ttp://www.sconul.ac.uk/groups/informationliteracy/papers/Sevenpillar.html (Accessed 7 May 2007).

Stripling, B. and Pitts, J. 1988. Brainstorm and bluesprints: teaching research as a thinking process. [Online]: http:// Virtualinquiry.com/inquiry/strpling.htm. (Accessed 20 March 2007).

Underwood, P. 2002. A case study in development through information literacy. A white paper prepared for UNESCO, the U.S. National Commission on Libraries and Information Science, and the National Forum on Information Literacy, for use at the Information Literacy meeting for experts, Prague, the Czech Republic. [Online]: $h t t p / / w w w . n c l i s . g o v / l i b i n t e r / i n f o l i t c o n f \& m e e t /$ papers/underwood-fullpaper.pdf (Accessed 7 May 2007). 